\title{
Relationship between Energy Consumption and Economic Growth in European Countries: Evidence from Dynamic Panel Data Analysis
}

\author{
Łukasz Topolewski
}

Citation: Topolewski, Ł.

Relationship between Energy

Consumption and Economic Growth in European Countries: Evidence from Dynamic Panel Data Analysis. Energies 2021, 14, 3565. https:// doi.org/10.3390/en14123565

\section{Academic Editor:}

Magdalena Radulescu

Received: 28 May 2021

Accepted: 8 June 2021

Published: 15 June 2021

Publisher's Note: MDPI stays neutral with regard to jurisdictional claims in published maps and institutional affiliations.

Copyright: (C) 2021 by the author. Licensee MDPI, Basel, Switzerland. This article is an open access article distributed under the terms and conditions of the Creative Commons Attribution (CC BY) license (https:/ / creativecommons.org/licenses/by/ $4.0 /)$.
Department of Economics, Faculty of Economic Sciences and Management, Nicolaus Copernicus University in Toruń, Gagarina 13A, 87-100 Toruń, Poland; lukasz.topolewski@umk.pl

\begin{abstract}
The aim of the article is to empirically verify the relationship between energy consumption and economic growth. The time scope of this study covers the period of 2008-2019. The scope of analyzed subjects covers 34 European countries, 27 of which are currently members of the European Union. European countries consume large amounts of energy, so it is worth investigating the effect of reducing energy consumption on the process of economic growth. For this purpose, dynamic panel models were used. The research methods included the use of dynamic panel models, taking into account the Arellano and Bond and Blundell and Bond estimators. The results made it possible to identify the relationship between energy consumption and economic growth. It was found that, in the short term, increases in production will result in a statistically significant increase in energy consumption. Importantly, in the long term, this impact is also statistically significant and positive. On the other hand, taking into account the second of the estimated models, it can be concluded that, in the short term, increases in energy consumption do not cause changes in the rate of economic growth. The verification of this relationship in the long term also does not confirm it. In summary, it can be stated that a one-way relationship (in the short and in the long term), directed from economic growth towards energy consumption, was identified.
\end{abstract}

Keywords: energy consumption; economic growth; European countries; dynamic panel model

\section{Introduction}

Economists focus on the efficient use of resources. They also note that progressing climate change could pose a threat to environmental sustainability. Therefore, attention should be paid to the relation between using resources efficiently and climate change and global warming. One of the causes of these phenomena is the high production of energy from traditional sources. The burning of fossil fuels is the main cause of an increase in $\mathrm{CO}_{2}$ emissions [1]. According to the report by the European Commission Joint Research Centre, nearly $90 \%$ of total emissions come from burning fossil fuels. Thus, it is worth conducting research on alternative methods of energy production, which might be both cheap and safe. One such solution is the production of renewable energy.

Fearing excessive greenhouse gas emissions, countries have taken steps to reduce them, as evidenced by the Kyoto climate agreement and the Paris climate agreement. The countries of the European Union are at the forefront of energy consumption, and thus emit large amounts of greenhouse gases. As a result, these countries have committed to reducing their greenhouse gas emissions by $40 \%$ by 2030 in comparison to the levels reported in 1990. However, reducing energy consumption may have a negative impact on production levels [2]. Moreover, ensuring access to affordable, sustainable, and modern energy is one of the goals of sustainable development, so it is worth studying the relationship between energy consumption and economic growth [3].

The aim of the article is to empirically verify the relationship between energy consumption and economic growth. For this purpose, dynamic panel models were used. The time 
scope of this study covers the period of 2008-2019. The scope of analyzed subjects covers 34 European countries, 27 of which are currently members of the European Union. The selection of the research sample was dictated by the cited data. Namely, European countries consume large amounts of energy, so it is worth investigating the effect of reducing energy consumption on the process of economic growth.

The article is structured as follows: The next section summarizes the research on the described issues, then presents a summary of the methods used in this research area and the methods and data used in this study. The fourth part describes the obtained empirical results, and the final paragraph concludes and discusses the obtained results.

\section{Literature Review}

The issues discussed in this article have been the subject of numerous studies. A lot of empirical research has been carried out to verify the relationship between energy consumption and economic growth, but the results are still inconclusive. The reason often cited for this is that researchers use various research methods, different samples, and different time ranges. However, these discrepancies should not preclude addressing this issue as part of a study. The differences of opinion stimulate discussion, and the result of this discussion may actually be a solution. All researchers should agree on one thingbinding decisions are needed. These decisions will affect both the quality of life of the present generation, as well as the wellbeing of all future generations. The results of such research constitute the basis for energy and environmental policies being implemented and authorized.

Four hypotheses can be found in the literature on the relationship between energy consumption and economic growth. The first is the growth hypothesis, which assumes that energy consumption plays an important role in the economic growth process both directly and indirectly, and complements other growth factors. Here, the relationship is directed from energy consumption towards economic growth. Consequently, any decisions regarding energy consumption will also affect productivity in the economy. In the framework of the second hypothesis, this approach is reversed. Namely, it is the increase in production that translates into an improvement of the standards of living throughout the population, which increases the level of energy consumption. The causal link is directed from economic growth towards energy consumption. Such a situation is referred to as a hypothesis conservation. In such circumstances, an energy-saving policy will not have a negative impact on the increase in production. The third hypothesis involves a feedback loop, i.e., energy consumption affects economic growth, and at the same time economic growth affects energy consumption. Under such conditions, limiting energy consumption will result in reduced production, while a lower rate of economic growth will result in lower energy demand. This last one-the neutrality hypothesis-describes a situation in which energy consumption and economic growth do not influence each other. As a result, reducing energy consumption or other such decisions will not have an impact on the rate of economic growth [4].

Kraft and Kraft's article was a breakthrough in research on the relationship between energy consumption and economic growth. Their study covered the period of 1947-1974, and focused on the economy of the United States. The conclusions showed a one-way relationship between economic growth and energy consumption [5]. It resulted in numerous discussions on the subject and more attention directed towards the described issues. Therefore, it is impossible to refer to all the empirical results, so the author will mention only a few examples.

Narayan and Popp studied the same relationship in a sample of 93 economies. The study covered the period of 1980-2006. The authors used the Granger causality approach. The analyzed relationship was confirmed only in some countries. The authors studied the relationship in certain regions. Out of 93 economies, 20 were European. In the long run, the link between energy consumption and economic growth was confirmed in only five countries [6]. 
Apergis and Tang analyzed the relationship between energy consumption and economic growth on a sample of 85 economies at different levels of development. The study covered the period of 1975-2007. In order to test this relationship, the Granger causality procedure modified by Toda and Yamamoto and Dolado and Lütkepol was used. The analyses confirmed the validity of the growth hypothesis in the case of 46 countries. They also observed that adding more control variables caused an increase in the number of economies where increased energy consumption resulted in increased production. Moreover, they found that the relationship might depend on the level of development of the countries selected. In relatively richer countries, the growth hypothesis was more often confirmed than in poor countries. They argued that poor countries relied more on labor-intensive industries, which are less dependent on energy consumption [7].

Ouedraogo studied the relationship between energy consumption and economic growth in 15 African countries belonging to the Economic Community of West African States. The time scope of the study was 1980-2008. To verify the abovementioned relationship, Ouedraogo used panel models of cointegration. She drew some interesting conclusions. Namely, in the short term, it was the change in production that affected energy consumption, and in the long term, it was energy consumption that affected the generated production. Thus, reducing energy consumption in the long term may lead to lower economic growth rates [8].

Chontanawat studied the relationship between energy consumption, carbon dioxide emissions, and economic growth. The study covered four countries of Southeast Asia: Indonesia, Malaysia, the Philippines, and Thailand. Chontanawat investigated the aforementioned relationship via time series, and he used the Johansen cointegration method and Granger causality for this purpose. His research confirmed the long-term relationship between energy consumption and economic growth. In all the cases, the relationship was directed only one way. However, the results varied among the economies. In Indonesia, Malaysia, and Thailand, the causation directed from economic growth to energy consumption was confirmed, while the opposite direction was reported for the Philippines. Thus, an energy-saving policy would not affect production in Indonesia, Malaysia, and Thailand. In contrast, in the Philippines, an energy-saving policy would result in lower production. Therefore, the author recommended promoting alternative energy sources, such as renewable energy [9].

Destek and Aslan analyzed the relationship between economic growth and the consumption of renewable and non-renewable energy. The research sample consisted of 17 emerging economies for the period 1980-2012. Bootstrap panel causality was used as a research method. Taking into account the consumption of renewable energy, the growth hypothesis was confirmed only for one economy (Peru), and the conservation hypothesis was confirmed for Colombia and Thailand. However, in the case of Greece and South Korea, the feedback hypothesis turned out to be correct. For the remaining 12 emerging economies, both variables had no influence on each other. The results were slightly different for the relationship between the consumption of non-renewable energy and economic growth In this case, the growth hypothesis was confirmed for China, Colombia, Mexico, and the Philippines, and a conservation hypothesis was confirmed for Egypt, Peru, and Portugal. A two-way relationship arose only in the case of Turkey. For the remaining emerging countries, no correlation between non-renewable energy consumption and economic growth was found [10].

Smolowić et al. investigated the relationship between renewable energy consumption and economic growth. The study covered the Member States of the European Union for the period of 2004-2018. As part of the study, the authors analyzed the relationship separately for the Member States that had joined the EU before 2004 and for the new members of the Community (countries that joined in 2004). To verify this relationship, they used dynamic panel models and, more specifically, the PMG estimator. The authors concluded that, in the long term, the consumption of renewable energy has a statistically significant impact on economic growth, in the case of both new members of the European Union and 
existing members. The results are interesting in the short term, as the impact of energy consumption on economic growth was negative for the new members of the community, while the impact for the existing EU members was statistically insignificant [3].

Radmehr, Henneberry, and Shayanmehr confirmed the positive impact of renewable energy consumption on production. They emphasized that non-renewable energy sources greatly contribute to the increase in production. At the same time, an increase in production causes an increase in the use of renewable energy. Therefore, it can be concluded that the relationship between economic growth and renewable energy consumption is directed both ways. Radmehr, Henneberry, and Shayanmehr studied the aforementioned relationship on a sample of 21 European countries. The study covered the period of 1995-2014 [2].

Coers and Sanders examined the relationship between energy consumption and gross domestic product on a sample of 40 OECD countries. The study covered the period of 1960-2000. An error correction model was used as the research method. The conclusion was that the causal relationship was directed from production to consumption of energy, but not the other way around. Therefore, energy should not be seen as a factor in increasing production [11].

Lee and Chang tested the studied relationship in 40 economies, 22 of which were developed economies and 18 were developing economies. The study covered the period of 1965-2002. In the study, they used a panel VAR model based on the generalized moment method. Lee and Chang confirmed the relationship between energy consumption and gross domestic product. The researchers estimated two separate models in groups of developed and developing countries. They concluded that in the group of developed countries, the studied relation is two-way in nature, i.e., GDP per capita affected energy consumption and energy consumption affected the GDP per capita. On the other hand, in the group of developing countries, a one-way relationship was confirmed. Namely, an increase in GDP per capita caused an increase in energy consumption. Thus, in the group of developing countries, the energy saving policy would not have a negative impact on the level of production [12].

Hasanov, Bulut, and Suleymanov also presented research on the discussed subject. Their study covered 10 oil-exporting developing countries in Eurasia in 1997-2014. Estimations were made via both the GMM method and Granger causality. Ultimately, they identified a one-way causal link directed from energy consumption to gross domestic product. Therefore, reducing energy consumption would reduce production [13].

Tang and Abosedra analyzed the impact of tourism, energy consumption, and political instability on economic growth. The research sample consisted of 24 countries in the Middle East and North Africa. The study covered the period of 2001-2009. They used both static panel models and dynamic panel models to verify the relations. In the dynamic panel models, they used the Arellano-Bond estimator. They stated that the increase in energy consumption had a statistically significant positive effect on economic growth [14].

Nayan et al. tested the relationship between economic growth and energy consumption on a sample of 23 countries. The study covered the period of 2000-2011. To test this relationship, they used dynamic panel models, namely the Blundell-Bond estimator. In their research, they found that the relationship was one-way in nature and was directed from GDP per capita to energy consumption. In the case of the opposite direction, the impact was statistically insignificant [15].

\section{Materials and Methods}

If the empirical research on the relationship between economic growth and energy consumption is studied, five research methods will be found: simple causality tests, twodimensional and multivariate VECM, and two-dimensional and multivariate VECM panel. Mehrara [16] arranged the studies via the methods used and divided them into four generations. The first one [5,17] is based on the traditional VAR model and Granger causality tests. In this approach, it was assumed that the time series were stationary. Later, objections to this assumption were made as the stationary nature of these variables was 
questioned. Due to these objections and the development of econometric methods within the next generation $[18,19]$, the unit root tests of time series and the cointegrating relation were used to study this relationship. A two-step procedure and error correction models were used to test the Granger causality. As part of the third generation [20,21], multi-stage error correction models using the Johansen procedure were used. Panel data were used in fourth generation models [22,23]. The main criticisms of the previous approach include the failure to take into account changes over time and the lack of differentiation between countries. Therefore, panel models of cointegration and panel error correction models have become more common.

Coers and Sanders [11] also considered fifth generation models [24,25], which use multidimensional vector error correction (VECM panel). These studies also have some limitations, but they are of a different nature. Namely, there is a problem with the availability of data on capital resources for a large number of countries.

In the empirical research in the literature on the relationship between energy consumption and economic growth, researchers have used various methods. Some of them used time series analysis, others used panel data analysis. The results of these studies vary, which often results from the methods used, the different time ranges, or the different groups of economies. Hasanov, Bulut, and Suleymanov [13] summarized the studies, considering the analyzed relation in crude oil-exporting countries. In these countries, a two-way relationship is found when panel data are used. Furthermore, the two-way relationship between energy consumption and economic growth is very rarely found in the case of time series analysis. In studies that used the VECM panel, a two-way relationship was often mentioned. The same stands for the use of panel FMOLS and panel DOLS. In the present summary, only three studies were cited, in which estimation methods based on the generalized method of moments were used. In the study by Tang and Abosedra [14], a one-way relationship between energy consumption and long-term economic growth (directed likewise) was found. On the other hand, in the study by Omri and Kahouli [26], there was a two-way relationship in the long term. A two-way relation was also found by Lee and Chang [12], but in their study it was a short-term relationship.

Given the results of the presented research, it might be observed that the choice of the test method is important for the final effect. In this article, the panel data were analyzed to allow for a broader point of view, and dynamic panel models were used for this purpose. Thus, the use of two-dimensional data facilitates the increase of the number of degrees of freedom and reduction of the problem of collinearity. When you analyze univariate data, a smaller number of degrees of freedom creates constraints. On the other hand, the analysis of panel data extends information about the units and enables a more complete interpretation of the model. Moreover, the analysis of panel data makes it possible to consider the diversity of objects. Among the explanatory variables, there are group effects that reflect this differentiation of units. Baltagi believes that panel data is better suited to analyze the dynamics of phenomena. If sufficiently long data sets are available, they can also be used to analyze changes in an economic policy. In addition, Baltagi pointed out that panel data allows for the measurement of effects that cannot be observed in the case of cross-sectional data or a time series [27].

Depending on the specifics and internal structure of the data, either static panel models or dynamic panel models can be estimated. This choice determines different estimation methods. If the data cover many objects in a short time horizon, then static panel models are used. Fixed effects models (FE) or random effects models (RE) are often used to estimate these kinds of models. If the time horizon is longer, then dynamic panel models can be used. Another criterion relevant when choosing the character of a model is the dynamics aspect. One of the modelled variables is economic growth, which is undoubtedly a dynamic process. As a result, panel models, unlike the time series, take into account the aspect of dynamics, which involves introducing a lagged dependent variable to the independent variables. This has certain consequences. Namely, the estimator that is used in static models loses consistency in the case of a dynamic model. This is because the lagged dependent 
variable is correlated with a random element. Especially when the time horizon of the data covered by the study does not go to infinity.

In the studies, estimation methods based on the generalized method of moments were used. The advantage of this type of method is that it can assume that a certain variable is endogenous in relation to the dependent variable.

The estimation of dynamic panel models differs significantly from the estimation of static models. Including the lagged dependent variable in the model correlates it with the disturbance term. The equation of such a model can be written as follows:

$$
Y_{i t}=\alpha_{i}+\beta_{1} * Y_{i, t-1}+\beta_{2} * Z_{i t}+\beta_{3} * X_{i t}+\delta_{t}+\varepsilon_{i t}
$$

where $i$ denotes the country and $t$ the year;

$Z_{i t}$-variable used to check influence on the dependent variable;

$X_{i t}$-variables controlling country $i$ and year $t$;

$\alpha_{i}$-individual effects;

$\delta_{t}$-time-specific effects;

$\varepsilon_{i t}$-error term.

The first difference estimator (Arellano and Bond) [28] or the system estimator (Arellano and Bover; Blundell and Bond) $[29,30]$ might be used to estimate this equation. In the first case, the differences are calculated, which allows for avoiding the above-mentioned correlation. In the second case, the equations are estimated in both increments and levels. When estimating the equation in levels, one can use the lagged first differences of this variable as instruments [27].

The data for the survey were taken from the Eurostat database [31] and the World Bank database [32]. The study used energy consumption expressed in thousands of tons per capita and gross domestic product per capita (in stable prices). Additionally, the gross fixed capital formation was included as control variable. This variable influences both the energy consumption and GDP per capita. The study covered the period 2008-2019 for 34 European economies, 27 of which are a member of the European Union, and the others included Iceland, Norway, United Kingdom, Montenegro, North Macedonia, Serbia, and Turkey.

The study used data on energy consumption, gross domestic product per capita, and gross capital formation. Table 1 presents descriptive statistics for the variables. As presented, there are some individual gaps in the data. Only the data on GDP changes are complete. It should be emphasized that the data gaps are small, which causes no problems in model estimation. The average energy consumption per capita in the analyzed countries was 3.58 tons. The inhabitants of Iceland consume the most energy among the analyzed countries, and the citizens of the North Macedonia the least. Taking into account the analyzed period, energy consumption decreased in most countries, but increased in five countries. The largest increase in energy consumption took place in Turkey, but it should be emphasized that the average energy consumption in this country is low. It is worth mentioning that despite significant energy consumption in Iceland, its consumption slightly increased. The average value of GDP per capita was nearly 39 thousand dollars. The richest country in terms of this measure was Luxembourg, and the poorest was the North Macedonia. The highest increase in GDP per capita was recorded in Ireland (56\%). It is worth noting that there was a decrease in the described measure in two countries, namely in Cyprus $(-2 \%)$ and in Italy $(-5 \%)$. The average investment value was nearly $\$ 121.5$ trillion. The highest average investments were recorded in Germany, and the lowest in Montenegro. It is worth pointing out that Ireland saw the largest increase in investment, while the largest decline occurred in Greece. 
Table 1. Descriptive statistics.

\begin{tabular}{cccccc}
\hline Variables & Observations & Mean & Standard Deviation & Min & Max \\
\hline EC & 405 & 3.58 & 2.83 & 1.21 & 18.69 \\
\hline GDP & 408 & $38,971.97$ & $18,197.39$ & $12,987.11$ & $113,940.24$ \\
\hline GCF & 406 & $121,417.96$ & $181,098.45$ & 779.38 & $811,529.13$ \\
\hline
\end{tabular}

Source: Own preparation.

It should be emphasized that the presented data were appropriately transformed into the rates of change of individual variables, which can be illustrated on the example of GDP per capita as follows:

$$
G D P_{i t}=\frac{G D P \text { per capita }_{i t}}{\text { GDP per capita }}
$$

$G D P_{i t}$-rate of change in GDP per capita

GDP per capita $a_{i t}$ - the level of GDP per capita for the subject $i$ in the $t$ period

GDP per capita $a_{i t-1}$ - the level of GDP per capita for the subject $i$ in the $t-1$ period

The remaining variables were transformed in an analogous way, and then all variables were logged.

\section{Results}

The first point of the study was the analysis of the degree of integration of individual variables. For this purpose, the Ima-Pesaran-Shin test and the Fischer-type test were used. The choice of the tests was dictated by minor gaps in the data because other tests require data completeness. Based on the results of both tests, it was found that the variables were stationary. The p-value in all the tests indicated the rejection of the null hypothesis in favor of an alternative hypothesis. Table 2 presents the results of the panel unit root tests.

Table 2. Panel Unit Root Tests.

\begin{tabular}{ccc}
\hline Variable & Im-Pesaran-Shin Test & Fischer-Type Test \\
\hline EC & 0.000 & 0.000 \\
\hline GDP & 0.000 & 0.000 \\
\hline GCF & 0.000 & 0.000 \\
\hline
\end{tabular}

Source: Own preparation.

The conducted study was divided into two stages. The starting point was the relation between energy consumption and gross domestic product per capita, and investments, in accordance with the following formula:

$$
E C_{i t}=f\left(G D P_{i t}, G C F_{i t}\right)
$$

$E C_{i t}$ - $\log$ of rate of change in energy consumption (tons of oil equivalent (TOE) per capita); $G D P_{i t}$ - log of rate of change in real gross domestic product per capita;

$G C F_{i t}-\log$ of rate of change in gross fixed capital formation.

Additionally, it was assumed that $G D P_{i t}$ was a predetermined variable and $G C F_{i t}$ was an exogenous variable. Thus, the following equation was used:

$$
E C_{i t}=\alpha_{i}+\beta_{1} * E C_{i, t-1}+\beta_{2} * E C_{i, t-2}+\beta_{3} * G D P_{i t}+\beta_{4} * G C F_{i t}+\delta_{t}+\varepsilon_{i t}
$$

A negative value was expected for the $G C F_{i t}$ variable. The implemented investments should use less energy than the previously used solution. Cost savings may be an incentive for enterprises to implement investments. 
In the next stage of this study, the second equation was estimated. This time the dependent variable was $G D P_{i t}$, while the independent variables included energy consumption and investments.

$$
G D P_{i t}=f\left(E C_{i t}, G C F_{i t}\right)
$$

It was assumed that the variable $E C_{i t}$ was an endogenous variable and that $G C F_{i t}$ was an exogenous variable. The following equation was estimated:

$$
G D P_{i t}=\alpha_{i}+\beta_{1} * G D P_{i, t-1}+\beta_{2} * G D P_{i t-2}+\beta_{3} * E C_{i t}+\beta_{4} * G C F_{i t}+\delta_{t}+\varepsilon_{i t}
$$

As part of the assessment of the obtained estimates, the autocorrelation tests proposed by Arellano-Bond and the Sargan/Hansen test were used.

Table 3 presents the results of the estimation of the parameters of Equation (3). Additionally, as an aid, the aforementioned equation was estimated using the pooled estimator and the fixed effects estimator. This activity determined the range of parameter changes for the lagged dependent variable. The parameter next to the lagged dependent variable should be in the range of $(-0.336)-(-0.244)$. The table shows the estimates derived using the Arellano-Bond and Blundell-Bond estimators. Both estimators are presented via a onestep and a two-step approach. Based on the results presented in Table 3, it might be stated that it is not possible to draw conclusions from the estimates using the Arellano-Bond estimator, because the parameter value for the lagged dependent variable is too high. It should be emphasized that the number of instruments was selected in accordance with the indications presented by Rodman [33]. In addition, the p-value in the Hansen test suggests that at a significance level of 5\% there is no reason to reject the null hypothesis. Thus, it can be concluded that the instruments in this model are appropriate. The ArellanoBond autocorrelation tests also indicate that there is no autocorrelation of the disturbance term. However, as mentioned earlier, conclusions cannot be drawn from estimates made using the Arellano-Bond estimator. Regarding the estimates made using Blundell-Bond, the parameter value for the lagged dependent variable decreased. Estimates using the one-step Blundell and Bond estimator also show too high of a parameter value for the lagged variable. Only estimates using the two-step Blundell and Bond estimator show appropriate of parameter value for the lagged variable. The $\mathrm{p}$-value in the second-order autocorrelation test suggests that there is no reason to reject the null hypothesis, which proves the lack of autocorrelation of the disturbance term. The p-value in Hansen's test also indicates that there is no reason to reject the null hypothesis. The instruments used can be considered appropriate. It is worth noting that the number of instruments used does not reduce the power of the Hansen test. The Hansen differential test also indicates that the instruments used are appropriate. Therefore, conclusions might be drawn from the estimates of the two-step Blundell-Bond estimator. Diagnostic tests showed that there is no autocorrelation of the disturbance term, and the instruments used are appropriate. As such, the statistically significant variables include the lagged dependent variable and GDP ${ }_{i t}$. It can be concluded that GDP per capita has a statistically significant impact on energy consumption. An increase in GDP per capita of $1 \%$ will increase energy consumption by an average of $0.46 \%$. The change in investment was statistically insignificant.

Based on Table 3, another model was estimated, considering only statistically significant variables. The impact of GDP on long-term energy consumption was investigated and such a relationship was confirmed. The impact of production changes on energy consumption was lower than for short-term consumption.

Table 4 presents estimates for Equation (5). The procedure was similar to the one used for estimating Equation (3). It was started with estimating the parameters using the pooled estimator and the fixed effects estimator. Thus, the ranges of the values for the parameters of the lagged dependent variable were obtained. The values should be in the range of $0.192-0.316$. It might be observed that the evaluation of the parameter with the lagged dependent variable in the estimation using the Arellano-Bond estimator is at the appropriate level. The results of the diagnostic tests suggest that the estimate is 
correct. The only thing that may raise some doubts is the relatively high p-value in the Hansen test. Therefore, it was decided that no conclusions should be drawn based on this estimate. The estimation with the two-stage Arellano-Bond estimator also cannot be used, as the parameter evaluation with the lagged dependent variable is too high. Blundell-Bond estimates could be used for inference. The comparison of both estimates suggests that the one-stage estimator is characterized by a lower standard error. Therefore, it was decided that this estimate would serve for the purpose of drawing relevant conclusions. Based on Arellano-Bond tests, no autocorrelation of the second random term was found. Moreover, the results of the Hansen test suggest that the instruments used were appropriate, same as the differential Hansen test. The statistically significant variables include the lagged dependent variable and investments. Energy consumption turned out to be statistically insignificant. Consequently, a $1 \%$ increase in gross capital formation will result in a $0.11 \%$ higher economic growth rate.

Table 3. Estimation results of energy consumption using data from 2008 to 2019.

\begin{tabular}{|c|c|c|c|c|}
\hline \multicolumn{5}{|c|}{ Variable Dependent: $\mathrm{EC}_{\mathrm{i}, \mathrm{t}}$} \\
\hline & FDGMM1 & FDGMM2 & SGMM1 & SGMM2 \\
\hline $\mathrm{EC}_{\mathrm{i}, \mathrm{t}-1}$ & $\begin{array}{c}-0.217^{* * *} \\
(0.062)\end{array}$ & $\begin{array}{c}-0.229 * * * \\
(0.050)\end{array}$ & $\begin{array}{c}-0.231^{* * *} \\
(0.066)\end{array}$ & $\begin{array}{c}-0.244^{* * *} \\
(0.055)\end{array}$ \\
\hline $\mathrm{EC}_{\mathrm{i}, \mathrm{t}-2}$ & $\begin{array}{l}-0.074 \\
(0.073)\end{array}$ & $\begin{array}{l}-0.097 \\
(0.063)\end{array}$ & $\begin{array}{l}-0.076 \\
(0.071)\end{array}$ & $\begin{array}{c}-0.084 \\
(0.060)\end{array}$ \\
\hline $\mathrm{GDP}_{\mathrm{i}, \mathrm{t}}$ & $\begin{array}{l}0.591 \text { ** } \\
(0.262)\end{array}$ & $\begin{array}{l}0.667 * * \\
(0.274)\end{array}$ & $\begin{array}{l}0.487^{*} \\
(0.285)\end{array}$ & $\begin{array}{l}0.460 \text { ** } \\
(0.212)\end{array}$ \\
\hline $\mathrm{GCF}_{\mathrm{i}, \mathrm{t}}$ & $\begin{array}{l}-0.031 \\
(0.061)\end{array}$ & $\begin{array}{c}-0.044 \\
(0.050)\end{array}$ & $\begin{array}{l}-0.049 \\
(0.063)\end{array}$ & $\begin{array}{l}-0.025 \\
(0.027)\end{array}$ \\
\hline Number of observations & 302 & 302 & 336 & 336 \\
\hline Number of countries & 34 & 34 & 34 & 34 \\
\hline Arellano-Bond test for AR(2) in differences ( $p$-value) & 0.434 & 0.891 & 0.473 & 0.662 \\
\hline Hansen test of joint validity of instruments ( $p$-value) & 0.152 & 0.152 & 0.126 & 0.112 \\
\hline Difference-in-Hansen test ( $p$-value) & - & - & 0.134 & 0.132 \\
\hline Number of instruments & 31 & 31 & 34 & 34 \\
\hline
\end{tabular}

Additional information: All models contain dummy variables of time. Standard errors are in parentheses. ${ }^{* * * * * * *}$ significance at levels $1 \%$, $5 \%$, and $10 \%$ respectively. Source: Own preparation.

Table 4. Estimation results of economic growth using data from 2008 to 2019.

\begin{tabular}{|c|c|c|c|c|}
\hline \multicolumn{5}{|c|}{ Variable Dependent: $\mathrm{GDP}_{\mathrm{i}, \mathrm{t}}$} \\
\hline & FDGMM1 & FDGMM2 & SGMM1 & SGMM2 \\
\hline $\mathrm{GDP}_{\mathrm{i}, \mathrm{t}-1}$ & $\begin{array}{c}0.285^{* * *} \\
(0.060)\end{array}$ & $\begin{array}{c}0.327^{* * * *} \\
(0.064)\end{array}$ & $\begin{array}{c}0.301 * * * \\
(0.047)\end{array}$ & $\begin{array}{c}0.299 * * * \\
(0.053)\end{array}$ \\
\hline $\mathrm{GDP}_{\mathrm{i}, \mathrm{t}-2}$ & $\begin{array}{l}-0.045 \\
(0.053)\end{array}$ & $\begin{array}{c}-0.839 \\
(0.036)\end{array}$ & $\begin{array}{c}0.003 \\
(0.060)\end{array}$ & $\begin{array}{c}0.011 \\
(0.057)\end{array}$ \\
\hline $\mathrm{EC}_{\mathrm{i}, \mathrm{t}}$ & $\begin{array}{c}0.084 \\
(0.075)\end{array}$ & $\begin{array}{c}0.073 \\
(0.048)\end{array}$ & $\begin{array}{c}0.047 \\
(0.067)\end{array}$ & $\begin{array}{c}0.056 \\
(0.079)\end{array}$ \\
\hline $\mathrm{GCF}_{\mathrm{i}, \mathrm{t}}$ & $\begin{array}{l}0.059 * * \\
(0.027)\end{array}$ & $\begin{array}{c}0.068^{* * *} \\
(0.021)\end{array}$ & $\begin{array}{c}0.108^{* * *} \\
(0.019)\end{array}$ & $\begin{array}{c}0.111^{* * *} \\
(0.020)\end{array}$ \\
\hline Number of observations & 302 & 302 & 336 & 336 \\
\hline Number of countries & 34 & 34 & 34 & 34 \\
\hline Arellano-Bond test for AR(2) in differences ( $p$-value) & 0.735 & 0.797 & 0.492 & 0.417 \\
\hline Hansen test of joint validity of instruments ( $p$-value) & 0.376 & 0.376 & 0.102 & 0.102 \\
\hline Difference-in-Hansen test ( $p$-value) & - & - & 0.160 & 0.160 \\
\hline Number of instruments & 30 & 30 & 33 & 33 \\
\hline
\end{tabular}

Additional information: All models contain dummy variables of time. Standard errors are in parentheses. ${ }^{* * * * * *}$ significance at levels $1 \%$, $5 \%$, and $10 \%$ respectively. Source: Own preparation. 
The above results were used to investigate the long-term relationship. Subsequent estimates showed that in the long term, an increase in energy consumption does not have a statistically significant impact on economic growth.

Once the results are presented, it is worth mentioning that both energy consumption, gross capital formation, and economic growth can contribute to environmental pollution. Thus, this impact should be considered before undertaking any activities. It is worth referring to the results of the research illustrating the above-mentioned issues. Zhand et al. indicated the positive relationship between economic growth or gross capital formation and $\mathrm{CO}_{2}$ emissions on the example of the Malaysian economy [34]. Similar studies were carried out on the examples of Japan [35], Mexico [36], China [37], and India [38].

\section{Discussion}

In the presented study, an attempt was made to verify the empirical relationship between energy consumption and economic growth. The verification was performed on a sample of 34 European economies in 2008-2019. The research methods included the use of dynamic panel models, using the Arellano and Bond and Blundell and Bond estimators. The results suggested the relationship between energy consumption and economic growth. It was found that in the short term, an increase in production will result in a statistically significant increase in energy consumption. Importantly, in the long term, this impact is also statistically significant and positive. On the other hand, considering the second of the estimated models, it can be concluded that in the short term, an increase in energy consumption does not cause changes in the rate of economic growth. Verification of this relationship in the long term also does not confirm it. That is, in the long term, an increase in energy consumption does not have a statistically significant effect on the rate of economic growth. In summary, it can be stated that a one-way relationship (in the short and in the long term) directed from economic growth towards energy consumption has been identified.

The obtained results suggest the existence of hypothesis conservation. At the same time, they do not differ from the results presented by Kraft and Kraft [5]. Additionally, Ouedraogo [8] obtained similar results in a short period of time on a sample of African countries. Ouedraogo also identified long-term dependencies directed from energy consumption to economic growth. Chontanawat [9] confirmed the analyzed dependence in the case of three Asian countries (Thailand, Indonesia, and Malaysia). It is worth mentioning that they had analyzed a time series. Destek and Aslan [10] also confirmed a one-way relationship for Colombia and Thailand for renewable energy and Egypt, Peru, and Portugal for non-renewable energy. The same exact direction of dependence was identified by Coers and Sanders [11]. Lee and Chang [12], on the other hand, included both developed and developing countries in their sample. They also obtained similar results. Similar results were also obtained by Nayan et al. [15].

On the basis of the obtained results and cross-referenced similar results indicated by other authors, it can be concluded that the energy-saving policy should not have negative influence on the economic growth processes. As a result, measures aimed at limiting the production of energy based on fossil fuels should be implemented, continued, and intensified. Consequently, $\mathrm{CO}_{2}$ emissions can be reduced. On the other hand, the constant drive to increase production will be reflected in energy consumption. Thus, country leaders should pay attention to the concept of sustainable development. High economic growth is a necessary factor for improving the living conditions of citizens, but it is not the only one. Hence, it is also beneficial to implement an energy-saving policy. Perhaps one solution is to introduce relevant tax solutions or impose penalties for excessive energy consumption. The analysis of data for European countries shows that energy consumption has been decreasing in recent years. This trend should be maintained. At the same time, it is recommended to popularize the consumption of renewable energy. Energy production based on renewable energy sources, including water, wind, and sun, does not adversely 
affect the natural environment. Solutions promoting its use can contribute to less pollution of the environment, and therefore better living conditions for all of us.

To conclude, the study examined the relationship between energy consumption and economic growth on the example of 34 European economies. Dynamic panel models were used to achieve this purpose. The applied econometric tools make the study an interesting contribution to the discussion. In recent years, the popularity of these instruments has been growing, and the applied subjective scope can be used as part of European integration initiative. At the same time, one should be aware that this study does not exhaust the topic and should be explored further by taking into account various factors, such as, for example, the different levels of development of the surveyed countries or different energy sources.

Funding: This research received no external funding.

Conflicts of Interest: The author declares no conflict of interest.

\section{References}

1. Piłatowska, M.; Geise, A.; Włodarczyk, A. The effect Of renewable and nuclear energy consumption on decoupling economic growth from $\mathrm{CO}_{2}$ emissions in Spain. Energies 2020, 13, 2124. [CrossRef]

2. Radmehr, R.; Henneberry, S.R.; Shayanmehr, S. Renewable energy consumption, $\mathrm{CO}_{2}$ emissions, and economic growth nexus: A simultaneity spatial modeling analysis of EU countries. Struct. Chang. Econ. Dyn. 2021, 57, 13-27. [CrossRef]

3. Smolović, J.C.; Muhadinović, M.; Radonjić, M.; Đurašković, J. How does renewable energy consumption affect economic growth in the traditional and new member states of the European Union? Energy Rep. 2020, 6, 505-513. [CrossRef]

4. Apergis, N.; Payne, J.E. Renewable and non-renewable energy consumption-growth nexus: Evidence from a panel error correction model. Energy Econ. 2012, 34, 733-738. [CrossRef]

5. Kraft, J.; Kraft, A. Relationships between energy and GNP. J. Energy Dev. 1978, 3, 401-403.

6. Narayan, P.K.; Popp, S. The energy consumption-real GDP nexus revisited: Empirical evidence from 93 countries. Econ. Model. 2012, 29, 303-308. [CrossRef]

7. Apergis, N.; Tang, C.F. Is the energy-led growth hypothesis valid? New evidence from a sample of 85 countries. Energy Econ. 2013, 38, 24-31. [CrossRef]

8. Ouedraogo, N.S. Energy consumption and economic growth: Evidence from the economic community of West African States (ECOWAS). Energy Econ. 2013, 36, 637-647. [CrossRef]

9. Chontanawat, J. Relationship between energy consumption, $\mathrm{CO}_{2}$ emission and economic growth in ASEAN: Cointegration and causality model. Energy Rep. 2020, 6, 660-665. [CrossRef]

10. Destek, M.A.; Aslan, A. Renewable and non-renewable energy consumption and economic growth in emerging economies: Evidence from bootstrap panel causality. Renew. Energy 2017, 111, 757-763. [CrossRef]

11. Coers, R.; Sanders, M. The energy-GDP nexus; addressing an old question with new methods. Energy Econ. 2013, 36, 708-715. [CrossRef]

12. Lee, C.C.; Chang, C.P. Energy consumption and GDP revisited: A panel analysis of developed and developing countries. Energy Econ. 2007, 29, 1206-1223. [CrossRef]

13. Hasanov, F.; Bulut, C.; Suleymanov, E. Review of energy-growth nexus: A panel analysis for ten Eurasian oil exporting countries. Renew. Sustain. Energy Rev. 2017, 73, 369-386. [CrossRef]

14. Tang, C.F.; Abosedra, S. The impacts of tourism, energy consumption and political instability on economic growth in the MENA countries. Energy Policy 2014, 68, 458-464. [CrossRef]

15. Nayan, S.; Kadir, N.; Ahmad, M.; Abdullah, S. Revisiting energy consumption and GDP: Evidence from dynamic panel data analysis. Procedia Econ. Financ. 2013, 7, 42-47. [CrossRef]

16. Mehrara, M. Energy consumption and economic growth: The case of oil exporting countries. Energy Policy 2007, 35, 2939-2945. [CrossRef]

17. Abosedra, S.; Baghestani, H. New evidence on the causal relationship between US energy consumption and gross national product. J. Energy Dev. 1989, 14, 285-292.

18. Glasure, Y.U.; Lee, A.R. Cointegration, error correction and the relationship between GDP and energy: The case of South Korea and Singapore. Resour. Energy Econ. 1997, 20, 17-25. [CrossRef]

19. Cheng, S.B.; Lai, W.T. An investigation of co-integration and causality between energy consumption and economic activity in Taiwan, Province of China. Energy Econ. 1997, 19, 435-444. [CrossRef]

20. Asafu-Adjaye, J. The relationship between energy consumption, energy prices and economic growth: Time series evidence from Asian developing countries. Energy Econ. 2000, 22, 615-625. [CrossRef]

21. Oh, W.; Lee, K. Causal relationship between energy consumption and GDP revisited: The case of Korea 1970-1999. Energy Econ. 2004, 26, 51-59. [CrossRef]

22. Lee, C.C. Energy consumption and GDP in developing countries: A cointegrated panel analysis. Energy Econ. 2005, 27, 415-427. [CrossRef] 
23. Al-Iriani, M.A. Energy-GDP relationship revisited: An example from GCC countries using panel Causality. Energy Policy 2006, 34, 3342-3350. [CrossRef]

24. Lee, C.C.; Chang, C.P. Energy consumption and economic growth in Asian economies: A more comprehensive analysis using panel data. Resour. Energy Econ. 2008, 30, 50-65. [CrossRef]

25. Narayan, P.K.; Smyth, R. Energy consumption and real GDP in G7 countries: New evidence from panel cointegration with structural breaks. Energy Econ. 2008, 30, 2331-2341. [CrossRef]

26. Omri, A.; Kahouli, B. Causal relationships between energy consumption, foreign direct investment and economic growth. Energy Policy 2013, 67, 913-922. [CrossRef]

27. Baltagi, B.H. Econometric Analysis of Panel Data, 3rd ed.; John Wiley \& Sons Ltd.: Chichester, UK, 2005; pp. 147-148.

28. Arellano, M.; Bond, S. Some tests of specification for panel data: Monte Carlo evidence and an application to employment equations. Rev. Econ. Stud. 1991, 58, 277-297. [CrossRef]

29. Arellano, M.; Bover, O. Another look at the instrumental variable estimation of error-components models. J. Econom. 1995, 68, 29-51. [CrossRef]

30. Blundell, R.; Bond, S. Initial conditions and moment restrictions in dynamic panel data models. J. Econom. 1998, 87, 115-143. [CrossRef]

31. Eurostat. Available online: https:/ / ec.europa.eu/eurostat (accessed on 9 March 2021).

32. World Bank. Available online: https:/ / www.worldbank.org/en/home (accessed on 3 June 2021).

33. Rodman, D. How to do xtabond2: An introduction to difference and system GMM in Stata. Stata. J. 2009, 9, 86-136. [CrossRef]

34. Zhang, L.; Li, Z.; Kirikkaleli, D.; Adebayo, T.S.; Adeshola, I.; Akinsola, G.D. Modeling $\mathrm{CO}_{2}$ emissions in Malaysia: An application of Maki cointegration and wavelet coherence tests. Environ. Sci. Pollut. Res. 2021, 28, 26030-26044. [CrossRef] [PubMed]

35. Adebayo, T.S.; Kirikkaleli, D. Impact of renewable energy consumption, globalization, and technological innovation on environmental degradation in Japan: Application of wavelet tools. Environ. Dev. Sustain. 2021. [CrossRef]

36. He, X.; Adebayo, T.S.; Kirikkaleli, D.; Umar, M. Consumption-based carbon emissions in Mexico: An analysis using the dual adjustment approach. Sustain. Prod. Consum. 2021, 27, 947-957. [CrossRef]

37. Soylu, Ö.B.; Adebayo, T.S.; Kirikkaleli, D. The imperativeness of environmental quality in China amidst renewable energy consumption and trade openness. Sustainability 2021, 13, 5054. [CrossRef]

38. Orhan, A.; Adebayo, T.S.; Genç, S.Y.; Kirikkaleli, D. Investigating the linkage between economic growth and environmental sustainability in India: Do agriculture and trade openness matter? Sustainability 2021, 13, 4753. [CrossRef] 